\title{
RESENHA
}

\section{DESVELANDO A INDÚSTRIA GLOBAL DA EDUCAÇÃO}

\author{
Newton Antonio Paciulli Bryan'
}

AMARAL, Marcelo Parreira do; STEINER-KHAMSI, Gita; THOMPSON, Christiane (Editors). Researching the Global Education Industry. Commodification, the Market and Business Involvement. Palgrave Mac Milan: Londres e Nova lorque, 2019. 295 p. ISBN 978-3-030-04235-6/ISBN 978-3-030-04236-3 (eBook).

A "indústria global da educação", fenômeno que vem se estendendo avassaladoramente em escala global nas primeiras décadas do século XXI, é - tema analisado criticamente na excelente coletânea de textos organizada e comentada por Marcelo Parreira do Amaral2, Gita SteinerKhamsi3 e Christiane Thompson ${ }^{4}$. O termo "indústria da educação" relacionado ao título dessa coletânea, já havia adquirido proeminência nos anos 1960, quando o professor de educação comparada e do desenvolvimento na Sorbonne e consultor da UNESCO, Le Than Khoi publicou sua obra "L'industrie de l'enseignement", elaborada através de estudos comparativos internacionais com base nos dados disponíveis na época, empregando a mesma lógica em vigor nas grandes empresas industriais de produção em massa para analisar os sistemas de ensino públicos. Entretanto, apesar da semelhança dos termos, há uma fundamental diferença conceitual e política em relação ao seu atual significado. O emprego da lógica da produção em massa para o estudo e organização dos sistemas

\footnotetext{
1 Doutor em Educação. Professor da Faculdade de Educação da Universidade Estadual de Campinas - UNICAMP. Orcid iD: http://orcid.org/0000-0002-9790-2443. E-mail: nbryan@unicamp.br

2 Professor de educação comparada na Universidade de Münsten, Alemanha.

3 Professora de educação comparada e internacional no Teachers College da Universidade Columbia, Nova lorque - EUA.

4 Professora de teoria e história da educação na Universidade Goethe, Frankfurt - Alemanha.
} 
educacionais, apesar de suscitar problemas largamente criticados desde essa época por cientistas sociais que demoliram suas bases, assim como o fizeram artistas geniais como Pink Floyd em The Wall, não punha em questão o caráter público da educação e a atribuição aos estados nacionais da responsabilidade de criar, financiar e administrar os sistemas nacionais de educação. Na presente coletânea, a indústria da educação, produto da mercantilização da educação e do envolvimento das grandes empresas em escala global nesse processo, é analisada no contexto da economia neo liberal difusa globalmente, que preconiza a privatização das atividades consideradas fundamentais para o funcionamento do Estado de Bem-Estar Social, entre elas, a educação.

Originado no período compreendido entre as duas Guerras Mundiais, os teóricos do neoliberalismo criaram um arsenal conceitual (Capital Humano, entre outros) e de dispositivos para sua implementação. Dois modos de ação inter-relacionados têm sido sua marca desde que atingiu o ápice de seu domínio a partir dos anos 1980: a privatização da escola pública e a introdução da lógica mercantil no setor público em escala global. Lógica que é um elemento essencial do que Foucault identificou como uma nova "governamentalidade" que se impõe ao setor público, ou a "nova razão do mundo" como Dardot e Laval (2009) a denominam. Autores críticos como Ball e Youdell (2008) já a haviam encontrado em vigor até mesmo na elaboração das políticas educacionais e, nesta coletânea, vários artigos mostram a extensão e a profundidade com que ela se impõe em escala global. Os organizadores da coletânea, Amaral e Thompson, ao conceituar a Indústria Global da Educação (GEI) apontam na sua apresentação algumas categorias centrais que permitem captar aspectos essenciais desse fenômeno complexo que desponta no cenário educacional em escala mundial: a economização (tradução das ações educacionais em linguagem economicista), marquetização, privatização, mercantilização (transformação da educação de um bem público em mercadoria submetida ao jogo do mercado) e financialização (tratar a educação como objeto de investimento e meio para obter lucro). 
O conjunto de artigos tem o mérito de apresentar ao leitor, uma grande gama de diferentes abordagens que se complementam e um amplo espectro de opções metodológicas para o exame crítico da GEl. Nessa linha, Stephen Ball5 emprega uma técnica etnográfica global de modo a realizar uma análise das redes de relações sociais, comerciais e discursivas. Redes que se compõem de "práticas globais, linguagens, pessoas e lugares, locais e eventos, e formas organizacionais" (p.25). Em um belo e inspirado artigo, Stephen Carney desafia os cânones do modo como se escreve sobre as políticas educacionais, que "limitam as possibilidades ou mesmo alternativas para um pensar radical" (p.254). Contra as convenções acadêmicas de análises unilaterais, propõe e consegue brilhantemente elaborar um texto que "dança entre três modos de apresentação: a científica, a meditativa e a poética". Dessa perspectiva multifacetada, a atuação da GEl determinando a política educacional do Nepal é apresentada sobre o pano de fundo constituído por um povo dotado de uma cultura sofisticada empobrecido material e culturalmente, para ser transformado em fonte de mão de obra barata para realizar serviços perigosos na construção civil no país, onde se instalou o centro de difusão regional das empresas internacionais de educação. Essas ações da GEl são apresentadas internacionalmente como políticamente neutras e envolvidas numa roupagem de racionalidade técnica-científica. Assim, Cristiane Thompson no seu estudo The Globalized Expert: On the Dissemination and Authorization of Evidence-Based Education aponta a emergência do que denomina expertise global (p. 203) fazendo a análise do discurso de Andreas Schleicher, coordenador de estudo sobre o PISA e diretor do departamento de educação da OCDE, a partir do material disponível no site TED (www.ted.com/talks); do banco de dados da Pearson "A curva de aprendizagem" e da plataforma de aprendizagem da Pearson - REVEL. Por meio dessa análise do discurso, Thompson mostra como esses discursos são direcionados a persuadir os interlocutores para serem também "global

\footnotetext{
${ }_{5}$ Professor da School of Education da Universidade de Londres.
} 
experts" e a aderirem ao projeto global da Pearson de inovação educacional baseado em evidências. Clara Fontdevila e Antoni Vergerb, em The Political Turn of Corporate Influence in Education: A Synthesis of Main Policy Reform Strategies, para analisar criticamente as estratégias de influência política de atores do setor privado sobre a formulação de políticas educacionais, utilizam a metodologia de revisão sistemática da literatura (SLR) sobre o tema publicado em revistas acadêmicas avaliadas por pares. Indo além das estratégias deliberadas utilizadas para influenciarem o setor público, os autores põem a lente sobre os artifícios, os "repertórios de ação" da GEl (p. 49). Nessa mesma linha, o artigo de Christopher Lubienski7 Advocacy Networks and Market Models for Education, parte da constatação de que o uso da evidência tida como cientificamente comprovada vem sendo utilizada cada vez mais como justificativa forte para as políticas educacionais - no documento base do programa No Child Left Behind de 2001 o termo "cientificamente baseado" foi empregado cem vezes (p. 69). Entretanto, ao contrário do esperado, constata que a rápida difusão mundial de políticas de corte neoliberal tem ocorrido apesar da falta de evidências de sua efetividade em atingir suas metas educacionais. Ocorre que "seus proponentes comumente referem-se à efetividade de tais abordagens em campos externos ao da educação e, então, - refletindo a tendência global geral de penetração do mercado em setores não mercantis - tem argumentado que essa lógica deveria ser estendida aos sistemas estatais de educação de massa. Apoiando-se nessa lógica, tem emergido uma infraestrutura para a rápida produção e disseminação de dados através de organizações e redes de apoio e persuasão (advocacy), grupos de pesquisa, lobistas políticos, blogueiros e outros formadores de opinião na internet" (p. 70). Assumindo o referencial neo-institucionalista de Meyer e Ramirez e o quadro teórico esboçado originalmente por Sabatier e associados de uma Advocacy Coallition Framework, Lubienski examina as redes constituídas por intermediários situados entre os pesquisadores e os

\footnotetext{
6 Professores da Universidade Autônoma de Barcelona.

7 Professor da Faculdade de Educação da Universidade de Indiana, EUA.
} 
formuladores de políticas que promovem, ou demonizam, propostas educacionais nos EUA, mostrando que elas atuam em um campo em que funcionam como "mercados" onde ideias são produzidas, consumidas, compradas e vendidas. No curso da exposição de sua pesquisa, Lubienski desvela a existência de relações assimétricas entre os promotores de ideias e os formuladores de políticas. Dada a profusão de dados existentes conclui que uma análise transacional das relações entre os atores envolvidos, tem um grande potencial para esclarecer o modo como são elaboradas e adotadas as políticas educacionais (p. 82).

O conjunto de textos põe à luz a atuação dos grandes grupos multinacionais que dominam o mercado educacional global, como a Pearson e as fundações relacionadas aos gigantes da área de informática, dentre as quais se sobressaem a Gates (Microsoft) e Dell. Mostram a relação dos órgãos multilaterais, criados após a Segunda Guerra pelos estados nacionais como agências para resolver problemas comuns (como a UNESCO, Banco Mundial e OCDE) com os interesses da GEl. Desse modo, a atuação da UNESCO, dada a sua importância no cenário mundial, é examinada de modo especial. $O$ artigo em que essa instituição multilateral é o principal objeto de análise - UNESCO, Education, and the Private Sector: A Relationship on Whose Terms? - Natasha Ridge and Susan Kippels8, não se caracteriza por uma abordagem claramente crítico analítica nem pela preocupação em romper paradigmas metodológicos e por discussões de natureza teórica. Entretanto, os autores apresentam evidências fundamentadas em profusão de dados obtidos por uma pesquisa rigorosamente vinculada aos cânones da pesquisa de base empírica, enfocando as cada vez mais sólidas relações da UNESCO com o setor privado para financiar seus projetos. Desde a saída dos EUA do quadro de nações participantes da UNESCO, em 1984, quando o governo Reagan a denunciou por não se alinhar às suas políticas fundadas no neoliberalismo, sendo logo seguido pela Inglaterra governada por Thacher, esse organismo

8 Pesquisadoras da Foundation for Policy Research, Emirados Árabes Unidos. 
multilateral vem enfrentando sérios problemas financeiros. Desde essa época, mesmo com o retorno da Inglaterra em 1998 e EUA em 2003, ela vem buscando persistentemente apoio financeiro de empresas e fundações privadas apontando como contrapartida sua tradição de organismo independente e comprometido com a qualidade da educação. Analisando o histórico dos acordos firmados pela UNESCO com entidades ligadas ao setor privado, as autoras expõem claramente como essas relações têm impactado suas políticas até a recente Declaração para a Educação em 2030 adotada pelo Fórum Mundial pela Educação de Incheon em 2015.

Dado o caráter global da Indústria da Educação, vários artigos examinam seu modo de operar em várias partes do mundo. O elaborado por Stephen Ball (Serial Entrepreneurs, Angel Investors, and Capex Light EduBusiness Start-Ups in India: Philanthropy, Impact Investing, and Systemic Educational Change) examina detalhadamente o caso indiano, mostrando como a associação do que vem sendo denominado "capitalismo social" e o "investimento de impacto" tem levado à criação de um sistema paralelo de educação (Shadow Education State) na Índia. Sigrid Hartong' no seu estudo The Transformation of State Monitoring Systems in Germany and the US: Relating the Datafication and Digitalization of Education to the Global Education Industry, mostra como as relações da GEl com os organismos públicos nos Estados Unidos vem transformando os sistemas estatais de monitoramento nesses países. Stephen Carney 10 Writing Global Education Policy Research analisa o processo de privatização realizado no Nepal pela GEl associada a fundações vinculadas a grandes empresas, como a Gates e Dell, e, entre outros países, fazendo referência ao Todos pela Educação no Brasil e a sua atuação junto a agências multilaterais (OCDE e UNESCO). Marvin Erfurth"1 em International Education Hubs as Competitive Advantage: Investigating the Role of the State as Power Connector in the Global

\footnotetext{
9 Professora da Universidade de Hamburg, Alemanha.

10 Professor do Departamento $O$ povo e a tecnologia da Universidade de Roskilde, Dinamarca.

11 Pesquisador da Universidde de Münster, Alemanha.
} 
Education Industry, desafiando a visão comum de que a emergência da GEI tem diminuído a importância do Estado capitalista, argumenta que o que vem ocorrendo não é a perda do papel central do Estado mas uma profunda mudança de seu papel. Logo, considera "imperativo compreender a mudança do papel do Estado no novo quadro político" (p. 183). Dentre outras, a nova função que o Estado vem assumindo no âmbito da GEl é a de um hub, conectando diversos interesses privados internacionais. Um caso típico dessa função é o que os Emirados Árabes Unidos vem desempenhando, como a pesquisa minuciosamente elaborada por Erfuth demonstra. Os Estados Unidos e Austrália constituem os casos da tendência em curso de montagem de enormes infraestruturas de dados por parte de redes de empresas fornecedoras de equipamentos e sistemas associadas às de tecnologia educacional analisados por Bob Lingard12 Em The Global Education Industry, Data Infrastructures, and the Restructuring of Government School System. Lingard mostra como essas infraestruturas impõem sua lógica às políticas educacionais delineando-se como uma espécie de "extragoverno" (extrastatecraft) - termo cunhado para denotar atividades externas ao governo, em adendo a ele ou em parceria com ele - de modo a estruturar os "assistêmicos sistemas educacionais" em vigor, constituindo-se como modalidade de privatização e de mercantilização da educação ainda pouco estudada. Recusa conceituação de infraestrutura de dados levando em conta somente seu aspecto técnico, infraestrutura computacional, e propõe uma abrangente, socio-técnica, que a expande incluindo redes de pessoas e políticas (p.136). O caso americano é constituido pelo programa InBloom financiado pela Fundação Gates, do fundador e membro da direção da Microsoft, Bill Gates. A Microsoft já havia atuado na área educacional desenvolvendo o SIF - School Interoperability Framework, um programa de código aberto que criou a oportunidade para as indústrias de tecnologia educacional introduzirem seus produtos no interior das escolas públicas. Iniciado nos EUA, o SIF logo se estendeu ao Reino Unido

12 Professor da Faculdade de Educação da Australian Catholic University. 
e Austrália. Chocando-se com o programa Race to the Top do governo Obama que visava à criação e direção pelo sistema educacional público de uma infraestrutura de dados, o InBloom suscitou uma ampla oposição à sua adoção na esfera pública. O caso australiano examinado é o The National Schools Interoperability Program. Como evidenciado pelo próprio título, trata-se da extensão do já citado SIF ao sistema escolar australiano.

Os impactos da GEl nas instituições educacionais e de pesquisa, na formulação de políticas públicas e na sociedade recebem um olhar especial, embora todos os autores também se preocupem com eles, em dois artigos. Marcelo Parreira do Amaral, em Embedding Education Research in the European Economic Imaginary?, partindo de uma reflexão sobre a atual agenda política europeia formulada no âmbito do programa Horizon 2020, em que é determinado que a pesquisa em ciências humanas e sociais seja integrada às prioridades nele estabelecidas. Amaral argumenta que a pesquisa educacional, assim como as de outras áreas abarcadas pelas ciências sociais "vem sendo reduzida ao seu potencial para a inovação técnico-científica e sua contribuição instrumental/prática para o enfrentamento dos desafios societais" (p.116). Além desse estreitamento dos objetivos da pesquisa social a fins utilitários a serviço do controle social pelo Estado, o autor mostra que essa tendência visa também relacionar a pesquisa científica com $\mathrm{O}$ imaginário econômico dominante de uma economia baseada no conhecimento. Amaral, para analisar o impacto dessa nova "governança epistêmica" da pesquisa educacional assim como na epistemologia social desse campo de pesquisa, toma como objeto de análise o caso da Alemanha, que considera exemplar (p.116). Com base nos dados dessa análise faz uma reflexão sobre o significado dessas transformações da política científica com teor utilitarista no processo de pesquisa educacional, que tende a eliminar seu caráter crítico social, fazendo com que a ciência seja um instrumento de legitimação da ordem social. S. Karin Amos ${ }^{13}$, em seu trabalho Digitization, Disruption, and the

13 Professora da Universidade de Tübingen, Alemanha. 
"Society of Singularities": The Transformative Power of the Global Education Industry, mostra como os programas educacionais baseados na digitalização e algoritmização (algorithmization) que vêm sendo projetados e implementados pela GEl não são meios neutros que visam apenas a servirem de novos instrumentos de apoio à gestão e ao processo de ensinoaprendizagem. Ao contrário, intencionalmente agem como promotores, desde as bordas dos sistemas e instituições, de uma profunda transformação do que entendemos como sistema escolar, escola ou universidade. A produção de Big Data sobre todos os aspectos da vida humana e sua manipulação através de algoritmos prenunciam $\circ$ que denomina algocracia, com profundas implicações sobre o que se entende por democracia, direitos humanos, homem e sociedade. Sua análise, dentre outros, dos programas eAdvising e Adaptative Learning implementados em grande universidade americana com 0 objetivo de apresentar dados favoráveis quanto ao desempenho acadêmico de seus alunos, baseados na coleta e processamento de uma pletora de dados sobre a totalidade de suas atividades, abarcando até os aspectos subjetivos mais profundos de suas vidas, aponta para a possibilidade, em um horizonte próximo, de uma tenebrosa distopia em que as funções de controle e aconselhamento possam ser realizadas por máquinas. Esse conjunto de ações da GEl ocorre no atual período denominado como "modernidade tardia" que não se posiciona como uma ruptura em relação à modernidade tal como a conhecemos, implicando, ao contrário, "continuidade, reconfiguração, rearranjo e a criação de novas relações e hierarquias opostas à simples ideia de substituição do velho pelo novo e diferente. Desse modo, o geral não desaparece, é substituído pelo singular e extraordinário. Os conceitos são reconfigurados" (p. 245). Assim, na modernidade tardia vai sendo constituída uma "sociedade de singularidades" em que são realçadas qualidades que tornam as instituições, cidades, regiões e também os indivíduos, únicos, singulares e especiais. Esse movimento de radical singularização dos indivíduos tem servido para a captação maciça de dados sobre suas vidas e 
subjetividades e na sua algoritmização como acontece com o emprego de programas do tipo do eAdvising.

Desse modo, o conjunto de artigos dessa coletânea apresenta um amplo painel sobre múltiplos aspectos da GEl com diferentes abordagens por autores atuando em múltiplos espaços nacionais que se complementam, examinando uma ampla bibliografia sobre o tema, casos típicos de várias regiões do mundo mostrando sua abrangência global e, mediante estudo comparativo, suas diferentes trajetórias. Apesar da rapidez com que a GEl vem ampliando sua área de atuação, os autores, além de apontarem seus impactos visíveis e possíveis eles mostram também suas deficiências e a oposição que suscitam por parte da sociedade civil ao tomarem consciência dos perigos que significa à construção e manutenção de sistemas educacionais democráticos a serviço dos interesses dos cidadãos.

O livro editado por Amaral, Steiner-Khansi e Thompson constitui importante e fundamental contribuição sobre o estado da arte da pesquisa sobre a Indústria Global da Educação que rapidamente vem se expandindo no Brasil, atuando em todos os níveis de ensino, o leitor brasileiro engajado na luta pela construção de uma educação de qualidade em uma sociedade democrática encontrará uma rica fonte de inspiração para a pesquisa acadêmica e ideias para a ação.

\section{Referências}

AMARAL, Marcelo Parreira do; STEINER-KHAMSI, Gita; THOMPSON, Christiane (Editors). Researching the Global Education Industry. Commodification, the Market and Business Involvement. Palgrave Mac Milan: Londres e Nova lorque, 2019. 295 p. ISBN 978-3-030-04235-6/ISBN 978-3-030-04236-3 (eBook). 